\title{
EFFECT OF LEVETIRACETAM ON HEALING OF EXCISION AND BURN WOUND MODELS IN WISTAR RATS
}

\author{
HUBA KH RASHID, NAVIN PATIL*, BALAJI 0, AMOD TILAK \\ Department of Pharmacology, Kasturba Medical College, Manipal Academy of Higher Education, Manipal, Karnataka, India. \\ Email: champion903@gmail.com
}

Received: 12 June 2018, Revised and Accepted: 26 December 2018

\section{ABSTRACT}

Objective: Levetiracetam (LEV) at lower doses (50 and $100 \mu \mathrm{g} / \mathrm{ml}$ ) has demonstrated antioxidant effect as per literature evidence. Hence, the aim of current study was to evaluate the action of LEV on wound healing with regard to its antioxidant properties.

Methods: A total of 30 adult rats of both the sexes weighing 150-250 g were randomly divided into five groups of six rats each. Excision and burn models were used. The five groups are as follows: Group 1: Normal saline, Group 2: Povidone-iodine, Group 3: Silver sulfadiazine, Group 4: LEV $50 \mathrm{mg} / \mathrm{kg}$, and Group 5: LEV $100 \mathrm{mg} / \mathrm{kg}$. Group 2 served as a standard control for excision wound model and Group 3 as a standard for burn wound model. LEV was given orally and all other drugs were given topically. The rate of wound contracture and period of epithelization were calculated from the initial wound size for all rats.

Results: In both the models, the rats treated with standard drug (povidone-iodine/silver sulfadiazine) and LEV showed faster rates of wound contraction, period of epithelization, and better antioxidant effect as compared to the control and the difference seen was statistically significant $(p<0.001)$. However, the rats treated with povidone-iodine/silver sulfadiazine showed faster rates of wound contraction and period of epithelization as compared to the rats treated with LEV and the difference was statistically significant $(\mathrm{p}<0.05)$.

Conclusion: The results of the study show that oral application of LEV enhanced the wound strength and accelerated healing of incision and burn wounds in rats. Further clinical trials can be done to prove the effect of LEV as an agent for wound healing.

Keywords: Wound contracture, Antioxidant, Povidone-iodine, Silver sulfadiazine.

(C) 2019 The Authors. Published by Innovare Academic Sciences Pvt Ltd. This is an open access article under the CC BY license (http://creativecommons. org/licenses/by/4. 0/) DOI: http://dx.doi.org/10.22159/ajpcr.2019.v12i3.27916

\section{INTRODUCTION}

Wound healing is the process of tissue repair involving the tissue response to injury. It is the natural reaction of the body consisting of the regeneration of the dermal and epidermal tissue. Several overlapping phases such as hemostasis, inflammation, proliferation, and maturation play vital roles in the process of wound healing [1]. Following an injury, the tissue gets disrupted and it is collagen which is required to repair and restore the normal structure and function. Healing process occurs immediately after infliction of the wound and takes place in four stages. Coagulation is the first phase that occurs to control the extensive blood loss due to injury. The next phase is characterized by inflammation and debridement of wound, followed by reepithelialization. Reepithelialization itself includes various stages such as proliferation, migration, and differentiation of squamous epithelial cells of the epidermis. Collagen deposition and remodeling in the dermis mark the last stage of the healing process [2]. For proper healing, all phases should occur accordingly, at a specific duration of time.

There are various factors that interfere with these phases, thus hindering the process of wound healing. Healing of the wound can be affected by various factors such as depth, size, location, age of the patient, nutritional status, and medications [3]. Microbial infection along with molecular oxygen and reactive oxygen species (ROS) plays a central role in the pathogenesis of wounds. These factors tend to cause cytotoxicity and delay wound healing [4]. A continuous generation of ROS such as superoxide radical and hydrogen peroxide is the hallmark of inflammation. Excess production of these ROS creates an imbalance with the protective antioxidant defense mechanisms of the body leading to oxidative stress [5]
The second-generation antiepileptic drug levetiracetam (LEV) is a new molecule that is clearly differentiated from the conventional antiepileptic drug by its pharmacologic properties and mechanism of action [6,7]. Although the exact molecular mechanism of action of LEV remains uncharacterized, it is known that this drug binds to synaptic vesicle protein $2 \mathrm{~A}$. By binding to this vesicle, this drug appears to act as modulator of synaptic vesicle exocytosis, leading to direct inhibition of synaptic neurotransmitter release. Moreover, LEV also has been previously demonstrated to protect against oxidative stress-induced neurotoxicity in several models of seizures $[8,9]$. Antioxidative enzymes and their isoforms constitute a cellular defense system against oxidative stress at the corresponding subcellular positions. At the same time, they permit the low concentrations of ROS to equilibrate, serving as signaling pathways to regulate the wound healing process [10]. LEV at lower doses (50 and $100 \mu \mathrm{g} / \mathrm{ml}$ ) prevented pro-oxidative changes, reducing the lipid peroxidation, nitrite contents, and catalase activity and increasing glutathione (GSH) levels [11]. A search of the literature showed that the effect of LEV on wound healing has not been assessed. In view of its known antioxidant, the present study is to evaluate the effect of LEV on wound healing in rats using excision and burn model in comparison with standard drugs such as povidone-iodine and silver sulfadiazine, respectively.

\section{METHODS}

The experiments were conducted according to the Committee for Prevention of Control and Supervision of Experimental Animals, and the Institutional Animal Committee approval was obtained.

\section{Animals}

Thirty adult male/female Wistar rats, weighing 150-250 g, were housed in polypropylene cages, maintained under the standard condition 
with temperature $\left(22-24^{\circ} \mathrm{C}\right), 12 \mathrm{~h}$ light $/ 12 \mathrm{~h}$ dark cycle, and relative air humidity of $40-60 \%$. Rats had continuous access to normocaloric standard rat pellet diet and tap water. The animals were acclimatized to the laboratory conditions for 1 week before the start of the experiment.

\section{Chemicals/drugs}

Stamp, ink, hot air oven, sterile syringes, gloves, forceps, scissors, metal cylinder for burn wound, scalpel, feeding needle, LEV, betadine ointment, silver sulfadiazine ointment, and normal saline were used.

\section{Experimental design}

The animals were divided into five groups of six animals each. Excision and burn wound model were used; Group 1: Normal control $(0.9 \%$ saline), Group 2: Standard control (povidone-iodine in excision wound model), Group 3: Standard control (Silver sulfadiazine in case of burn wound model), Group 4: LEV $50 \mathrm{mg} / \mathrm{kg}$ for excision model, and Group 5: LEV $50 \mathrm{mg} / \mathrm{kg}$ for burn model. Standard drugs were used as a topical application and LEV was given orally daily until wound healing was complete or for 21 days whichever was earlier. The dose of all drugs was chosen based on previous literature [11].

\section{Excision wound model}

The excision wounds were created under ketamine anesthesia $(50 \mathrm{mg} / \mathrm{kg}$ body weight), given intramuscularly after working area sterilization. The rats were shaved, and skin was cleaned with the cotton swab soaked in $70 \%$ alcohol. A round skin area of $500 \mathrm{~mm}^{2}$ approximately was demarcated in diameter, on the dorsal thoracic region $5 \mathrm{~cm}$ away from the ears as described by Morton and Malone [12]. The entire full thickness of the skin from the demarcated area was excised. Wound contraction from the initial wound size and the period epithelization was calculated on the days $4,8,12$, and 16 .

$$
\begin{aligned}
& \text { WordConcentration }= \\
& \underline{\text { initial woundsize }- \text { specificday woundsize }} \times 100 \\
& \text { initial woundsize }
\end{aligned}
$$

\section{Burn wound model}

Partial thickness burn wound was inflicted, on overnight-starved animals under pentobarbitone $(30 \mathrm{mg} / \mathrm{kg}$, i.p.) by pouring hot molten wax at $80^{\circ} \mathrm{C}$ into a metal cylinder of $300 \mathrm{~mm}^{2}$ circular openings placed on the shaved back of the animal. Treatment started on the day 2 after the injury. Wound contraction from the initial wound size and the period epithelization was calculated on the days 4, 8, 12, and 16 .

\section{Histopathological analysis}

Skin biopsy was taken using punch biopsy needle on the day 16 after completion of treatment using each model. The biopsied tissue was sent for histopathological analysis. Skin specimens from rats of three groups (for each model) were collected in $10 \%$ buffered formalin, and after the usual processing, 5- $\mu \mathrm{m}$ thick sections were cut and stained with hematoxylin and eosin. Sections were qualitatively assessed under the light microscope and graded with respect to fibroblast proliferation, collagen formation, epithelization, and keratinization.

\section{Statistical analysis}

One-way analysis of variance along with Tukey's post hoc analysis were used to compare between the groups and a p value of $<0.05$ was taken as significance. Analysis was down using SPSS version 23.0.

\section{RESULTS}

In both excision and burn models, the rats in all the groups showed adequate healing with wound contraction and epithelialization of the wound by the $20^{\text {th }}$ day of the experiment. When the rate of wound contraction was assessed, the rats treated with standard drugs and LEV showed faster rates of wound contraction as compared to the rats treated with normal saline which served as control and the difference seen was statistically significant. The rats treated with the test drug, i.e., LEV given orally showed the rate of wound contraction that was comparable to that seen with the standard drugs until $8^{\text {th }}$ day and there was no statistically significant difference. However, the rats treated with povidone-iodine and silver sulfadiazine showed faster rates of wound contraction as compared to the rats treated with LEV as seen on the days $12^{\text {th }}$ and $16^{\text {th }}$ after the wound was inflicted (Tables 1 and 2). The period of epithelialization in the standard and test groups was shorter as compared to that seen in the control group and the difference was statistically significant. The period of epithelialization in the standard group was shorter as compared to the test group and the difference showed statistical significance (Tables 3 and 4).

Histopathological analysis was performed for both the models as shown in Figs. 1 and 2. Both standard and test groups showed better healing when compared with control. The control group showed subnormal repaired tissue. Epidermis and dermis were not clearly separated. Hair follicles and the muscular tissue are also seen in the primitive stage in the deeper parts with minimal neovascularization. Superficial parts have immature stroma with scanty blood vessels. The standard group showed bundles of connective fibers characteristic of collagen maturation. Neovascularization has taken place, and the blood vessels are clearly seen. More superficial parts of the section show a dense population of cells which are closely packed, indicating that the stroma is lacking or yet to form. Distinction between dermis and epidermis was noted. In the LEV-treated group, there was apparent distinction

\begin{tabular}{|c|c|c|c|c|c|}
\hline \multirow[t]{2}{*}{ Groups } & \multirow[t]{2}{*}{ Drug } & \multicolumn{4}{|c|}{ Wound contraction $\%$ in mean $\pm S E M$} \\
\hline & & Day 4 & Day 8 & Day 12 & Day 16 \\
\hline 1 & Control (saline) & $21.91 \pm 0.29$ & $43.18 \pm 0.52$ & $68.43 \pm 0.31$ & $81.83 \pm 0.32$ \\
\hline 2 & Povidone-iodine (topical) & $31.11 \pm 0.57^{\mathrm{a}}$ & $52.04 \pm 0.64^{\mathrm{ab}}$ & $78.30 \pm 0.46^{\mathrm{ab}}$ & $93.27 \pm 0.39^{\mathrm{ab}}$ \\
\hline 3 & LEV (oral) & $30.17 \pm 0.39^{\mathrm{a}}$ & $51.07 \pm 0.36^{\mathrm{a}}$ & $76.58 \pm 0.55^{\mathrm{a}}$ & $91.67 \pm 0.31^{\mathrm{a}}$ \\
\hline
\end{tabular}
between epidermis and dermis. Dermis has well-developed connective

Table 1: Effect of LEV on the rate of wound contraction in an excision wound

Values are expressed as mean \pm S.E.M. Statistical analysis was done using one-way ANOVA followed by Tukey's post hoc test. ${ }^{\mathrm{a} p}<0.01$ versus control, ${ }^{\mathrm{b}} \mathrm{p}<0.05$ versus LEV. ANOVA: Analysis of variance, SEM: Standard error of the mean, LEV: Levetiracetam

Table 2: Effect of LEV on the rate of wound contraction in a burn wound

\begin{tabular}{llllll}
\hline \multirow{2}{*}{ Groups } & Drug & \multicolumn{2}{l}{ Wound contraction \% in mean \pm SEM } & & Day 12 \\
\cline { 2 - 5 } & & Day 4 & Day 8 & $68.43 \pm 0.31$ & Day 16 \\
\hline 1 & Control (saline) & $21.91 \pm 0.29$ & $43.18 \pm 0.52$ & $81.83 \pm 0.32$ \\
2 & Silver sulfadiazine (topical) & $30.11 \pm 0.57^{\mathrm{a}}$ & $49.04 \pm 0.64^{\mathrm{ab}}$ & $82.30 \pm 0.46^{\mathrm{ab}}$ & $96.27 \pm 0.39^{\mathrm{ab}}$ \\
3 & LEV (oral) & $29.17 \pm 0.39^{\mathrm{a}}$ & $48.57 \pm 0.36^{\mathrm{a}}$ & $81.58 \pm 0.55^{\mathrm{a}}$ & $90.67 \pm 0.31^{\mathrm{a}}$ \\
\hline
\end{tabular}

Values are expressed as mean \pm S.E.M. Statistical analysis was done using one-way ANOVA followed by Tukey's post hoc test. ${ }^{\mathrm{a}} \mathrm{p}<0.05$ versus control, ${ }^{\mathrm{b}} \mathrm{p}<0.05 \mathrm{versus}$ LEV.

ANOVA: Analysis of variance, SEM: Standard error of the mean, LEV: Levetiracetam 


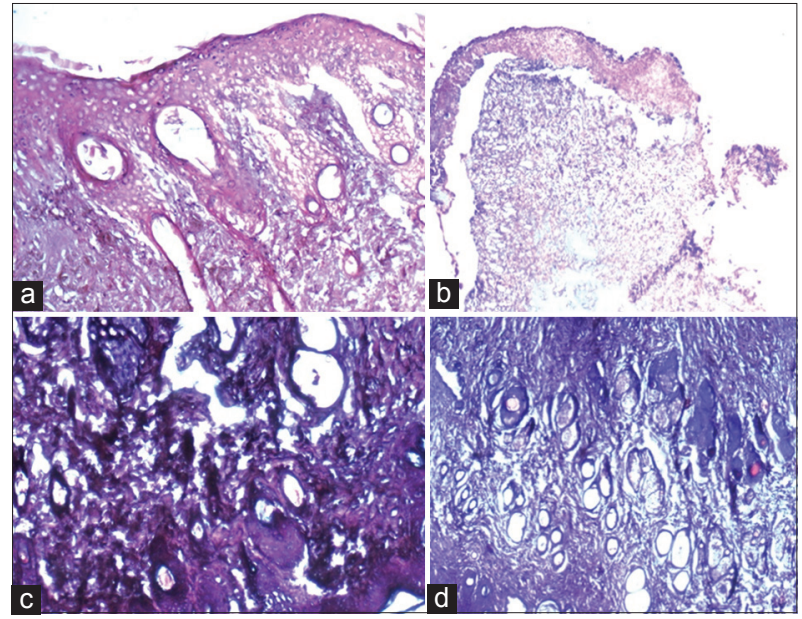

Fig. 1: Excision wound model histopathological analysis.

(a) Normal control, (b) Standard povidone-iodine,

(c) Levetiracetam (LEV) $50 \mathrm{Mg} / \mathrm{Kg}$, (d) LEV $100 \mathrm{Mg} / \mathrm{Kg}$

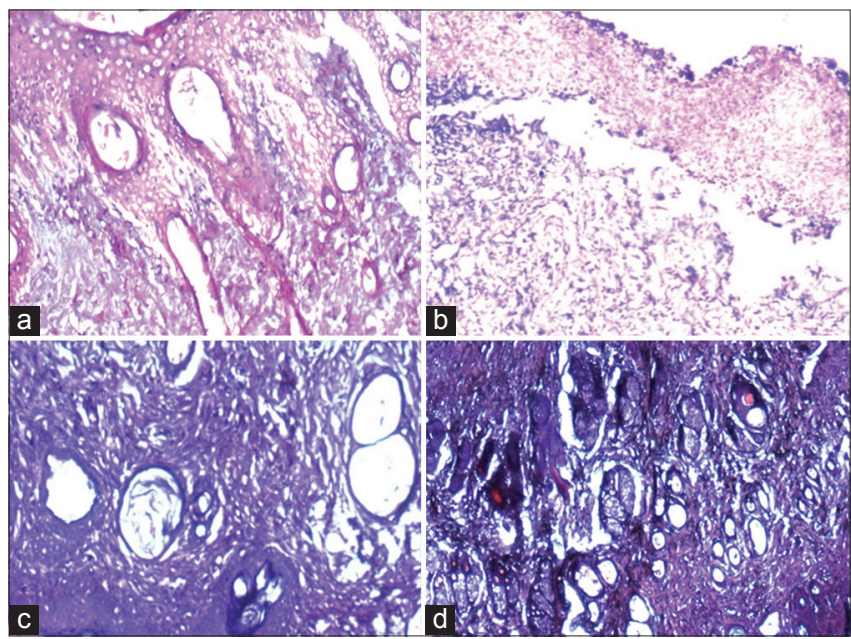

Fig. 2: Burn wound model histopathological analysis. (a) Normal control, (b) Standard silver sulfasalazine, (c) Levetiracetam (LEV) $50 \mathrm{Mg} / \mathrm{Kg}$, (d) LEV $100 \mathrm{Mg} / \mathrm{Kg}$

tissue. Cell is clearly distinct with matured collagenous connective tissue. Blood vessels are well developed, and the glands and muscular tissues are very clearly seen. Healing is comparable to the standard treatment group.

\section{DISCUSSION}

This study was undertaken to evaluate the effect of oral LEV on healing of excision and burn wounds in rats. Two models were used to assess wound healing properties of LEV in excision and burn wound. Although all two models are models of acute wound, burn wound differs in many aspects with other wounds. Hence, burn wound model was included. Further, these wounds heal by different models (healing by primary or secondary intention) and various aspects of wound healing can be studied only in certain models. Hence, different models were used in our studies [13]. Rat was used as a model due to the ease of availability and abundant literature available for it. Male rats were used to avoid the confounding effect of estrogen on wound healing [14]. Size of wound is an important predictor of wound healing. The results of the study show that oral application of LEV enhanced the wound strength and accelerated healing of excision and burn wounds in rats.

LEV is a pyrrolidine, the rechemically pure S-enantiomer of -ethyl2-oxo-1pyrrolidineacetamide. LEV exhibits a novel pharmacological
Table 3: Effect of LEV on the period of epithelialization in an excision wound

\begin{tabular}{lll}
\hline Group (n=6) & Drug & $\begin{array}{l}\text { Period of epithelialization (days) } \\
\text { mean } \pm \text { S.E.M }\end{array}$ \\
\hline Control & Paraffin wax & $18.67 \pm 0.21$ \\
Standard & Povidone-iodine & $15.83 \pm 0.31^{\mathrm{ab}}$ \\
Test & LEV & $16.83 \pm 0.17^{\mathrm{a}}$ \\
\hline
\end{tabular}

Values are expressed as mean \pm S.E.M. Statistical analysis was done using one-way ANOVA followed by Tukey's post hoc test. ${ }^{a} \mathrm{p}<0.001$ versus control, ${ }^{\mathrm{b}} \mathrm{p}<0.05$ versus LEV. ANOVA: Analysis of variance, SEM: Standard error of the mean, LEV: Levetiracetam

Table 4: Effect of LEV on the period of epithelialization in a burn wound

\begin{tabular}{lll}
\hline Group (n=6) & Drug & $\begin{array}{l}\text { Period of epithelialization (days) } \\
\text { mean } \pm \text { S.E.M }\end{array}$ \\
\hline Control & Paraffin wax & $18.83 \pm 0.17$ \\
Standard & Silver sulfadiazine & $15.50 \pm 0.22^{\text {ab }}$ \\
Test & LEV & $16.50 \pm 0.22^{\mathrm{a}}$ \\
\hline
\end{tabular}

Values are expressed as mean \pm S.E.M. Statistical analysis was done using one-way ANOVA followed by Tukey's post hoc test. ${ }^{\mathrm{a}} \mathrm{p}<0.001$ versus control, ${ }^{b} p<0.05$ versus LEV. ANOVA: Analysis of variance, SEM: Standard error of the mean, LEV: Levetiracetam

profile in so far as it inhibits partial and secondary generalized tonicclonic seizures in the kindling model. The mechanism of action of LEV is uncertain. No evidence for its action on the voltage-gated $\mathrm{Na}+$ channel or either gamma-aminobutyric acid or glutamate-mediated synaptic transmission has emerged. The correlation between the binding affinity of LEV analogs and their potency toward audiogenic seizures suggest that a synaptic vesicle protein, SV2A, mediates an anticonvulsant effect of LEV. LEV is rapidly and almost completely absorbed after oral administration. $95 \%$ of the drug is excreted in urine. $65 \%$ excreted unchanged and $24 \%$ of the drug metabolized by hydrolysis of acetamide group [7].

Epithelialization is the process of restoring the stratified epithelium following injury. This involves migration and proliferation of epithelial cells. The migration is further facilitated by degradation of extracellular matrix in the way of keratinocyte progression by different metalloproteinases. When a layer of epithelial the cell is established, migration and proliferation stop and differentiation of the cell starts to provide stratified epithelium. Wound contraction, manifesting as shrinkage of wound area, starts around $4^{\text {th }}$-day postwounding and is completed by $16^{\text {th }}$ day [15]. In the present study, LEV significantly accelerated wound healing in excision wound and showed better wound contraction than normal saline (control) treatment. In burn wound model, LEV-treated group enhanced epithelialization as well as the rate of wound contraction. Burn wound is usually associated with ischemia followed by restoration of blood flow.

Antioxidants are believed to quench free radicals. Free radicals are molecules with singlet unpaired electron which makes them highly reactive. Oxidative free radicals generated by metabolic reactions create a chain reaction leading to membrane lipid peroxidation and DNA damage [10]. Antioxidants lower inflammation markers and facilitate wound healing by promoting fibroblasts migration [10]. LEV has rich antioxidant property. Mechanism of LEV involves antioxidant properties. Moreover, LEV also has been previously demonstrated to protect against oxidative stress-induced neurotoxicity in several models of seizures [8,9]. LEV and clonazepam, mainly at lower doses ( 50 and $100 \mu \mathrm{g} / \mathrm{ml}$ ), and similarly to Vitamin C, prevented pro-oxidative changes, reducing the lipid peroxidation, nitrite contrite contents, and catalase activity and increasing GSH levels [11]. 


\section{CONCLUSION}

LEV demonstrated to have an antioxidant effect can accelerate wound healing. The rate of wound contraction with oral LEV was as fast as standard topical treatment for burn wound and excision wound. Hence, proper clinical trials can be designed, and various wound models can be used to evaluate the effect of LEV on healing

\section{AUTHORS' CONTRIBUTION}

Special thanks to Department of Pharmacology for their sincere support in conducting the research

\section{CONFLICTS OF INTEREST}

There were no conflicts of interest.

\section{REFERENCES}

1. Diegelmann RF, Evans MC. Wound healing: An overview of acute, fibrotic and delayed healing. Front Biosci 2004;9:283-9.

2. Karodi R, Jadhav M, Rub R, Bafna A. Evaluation of the wound healing activity of crude extract of Rubia cordifolia L. (Indian madder) in mice. Int J Appl Res Nat Prod 2009;2:12-8

3. Guo S, Dipietro LA. Factors affecting wound healing. J Dent Res 2010;89:219-29.

4. Vinothapooshan G, Sundar K. Wound healing effect of various extracts of Adathoda vasica. Int J Pharm Bio Sci 2010;1:530-6.

5. Patil N, Vaishnav R, Thanusubramanian H, Holla SN, Manohar HD, Bairy KL. Formulation and evaluation of the hydroalcoholic extract of Caesalpinia pulcherrima (Stem bark) on wound healing model in
Wistar rats. Int J Adv Res 2015;3:648-54.

6. Gibbs JE, Walker MC, Cock HR. Levetiracetam: Antiepileptic properties and protective effects on mitochondrial dysfunction in experimental status epilepticus. Epilepsia 2006;47:469-78.

7. Lyseng-Williamson KA. Levetiracetam: A review of its use in epilepsy. Drugs 2011;71:489-514.

8. Oliveira AA, Almeida JP, Freitas RM, Nascimento VS, Aguiar LM, Júnior $\mathrm{HV}$, et al. Effects of levetiracetam in lipid peroxidation level, nitrite-nitrate formation and antioxidant enzymatic activity in mice brain after pilocarpine-induced seizures. Cell Mol Neurobiol 2007;27:395-406.

9. Ueda Y, Doi T, Takaki M, Nagatomo K, Nakajima A, Willmore LJ, et al. Levetiracetam enhances endogenous antioxidant in the hippocampus of rats: In vivo evaluation by brain microdialysis combined with ESR spectroscopy. Brain Res 2009;1266:1-7.

10. Kurahashi T, Fujii J. Roles of antioxidative enzymes in wound in wound healing. J Dev Biol 2015;3:57-70.

11. Oliveira AD, Linhares MI, Filho AJ, Rios ER, Lima CN, Venancio ET, et al. Antioxidant properties of antiepileptic drugs levetiracetam and clonazepam in mice brain after in vitro-induced oxidative stress. Afr J Pharm Pharmacol 2016;10:278-88.

12. Morton JJ, Malone MH. Evaluation of vulneray activity by an open wound procedure in rats. Arch Int Pharmacodyn Ther 1972;196:117-26.

13. Ansell DM, Holden KA, Hardman MJ. Animal models of wound repair: Are they cutting it? Exp Dermatol 2012;21:581-5.

14. Chung KT, Wong TY, Wei CI, Huang YW, Lin Y. Tannins and human health: A review. Crit Rev Food Sci Nutr 1998;38:421-64.

15. Pastar I, Stojadinovic O, Yin NC, Ramirez H, Nusbaum AG, Sawaya A, et al. Epithelialization in wound healing: A comprehensive review. Adv Wound Care (New Rochelle) 2014;3:445-64. 